\title{
NMR spectroscopy of RNA duplexes containing pseudouridine in supercooled water
}

\author{
KERSTEN T. SCHROEDER, ${ }^{1}$ JACK J. SKALICKY, ${ }^{2,3}$ and NANCY L. GREENBAUM ${ }^{1,2}$ \\ ${ }^{1}$ Department of Chemistry and Biochemistry, Florida State University, Tallahassee, Florida 32306-4390, USA \\ ${ }^{2}$ National High Magnetic Field Laboratory, Tallahassee, Florida 32306-4390, USA
}

\begin{abstract}
We have performed NMR experiments in supercooled water in order to decrease the temperature-dependent exchange of protons in RNA duplexes. NMR spectra of aqueous samples of RNA in bundles of narrow capillaries that were acquired at temperatures as low as $-18^{\circ} \mathrm{C}$ reveal resonances of exchangeable protons not seen at higher temperatures. In particular, we detected the imino protons of terminal base pairs and the imino proton of a non-base-paired pseudouridine in a duplex representing the eukaryotic pre-mRNA branch site helix. Analysis of the temperature dependence of chemical shift changes (thermal coefficients) for imino protons corroborated hydrogen bonding patterns observed in the NMR-derived structural model of the branch site helix. The ability to observe non-base-paired imino protons of RNA is of significant value in structure determination of RNA motifs containing loop and bulge regions.
\end{abstract}

Keywords: pseudouridine; branch site; RNA; supercooled water; NMR; imino protons

\section{INTRODUCTION}

Determination of nucleic acid structures by NMR methodology relies upon numerous inter- and intramolecular distances and angular constraints. Interactions involving exchangeable imino and amino protons provide important information about hydrogen bonds and stabilizing interactions with water molecules, particularly for analysis of unusual structural motifs of folded RNA molecules. A sizable fraction of labile protons in RNA $\left(-\mathrm{NH},-\mathrm{NH}_{2}\right.$, and $\left.-2^{\prime} \mathrm{OH}\right)$, however, exchange rapidly with solvent at $\mathrm{T}>0^{\circ} \mathrm{C}$. As a result, they are exchange broadened beyond detection, thus escaping use in structural studies. Sufficiently decreased temperature slows chemical exchange between these protons and water, allowing for their direct detection and recruitment for structural study. Borer and colleagues (Kerwood et al. 2001) detected resonance peaks of imino protons of terminal nucleotides at $-6^{\circ} \mathrm{C}$ that were not observed at $0^{\circ} \mathrm{C}$. In order to monitor non-base-paired

${ }^{3}$ Current address: Department of Biochemistry, University of Utah School of Medicine, Salt Lake City, UT 84132-3201, USA.

Reprint requests to: Nancy L. Greenbaum, Department of Chemistry and Biochemistry, Dittmer Laboratory of Chemistry, Florida State University, Tallahassee, FL 32306-4390, USA; e-mail: nancyg@chem.fsu.edu; fax: (850) 644-8281.

Article and publication are at http://www.rnajournal.org/cgi/doi/ 10.1261/rna.2270205. imino protons, however, a method to achieve temperatures as low as $-20^{\circ} \mathrm{C}$ without freezing is desirable.

Exploiting the empirical observation that the freezing point of water decreases proportionally with volume (Angell 1982), Poppe and van Halbeek (1994) studied sucrose in glass capillary tubes at $-17^{\circ} \mathrm{C}$, allowing measurement of $-\mathrm{OH}$ proton chemical shifts and ${ }^{3} \mathrm{~J}_{\mathrm{HH}}$ couplings. The capillary technique was extended to BPTI, ubiquitin, dATP, and dGTP in supercooled water at about $-18^{\circ} \mathrm{C}$ (Skalicky et al. 2000, 2001).

In this study, we have investigated the structural role of exchangeable protons of pseudouridine $(\Psi)$, a rotational isomer of uridine attached to its ribose through $\mathrm{C} 5$, in RNA duplexes. $\Psi$ has two imino nitrogen atoms, $\Psi \mathrm{N}^{1} \mathrm{H}$ and $\Psi \mathrm{N}^{3} \mathrm{H}$, both of which are protonated at physiological $\mathrm{pH}$ (Hall and McLaughlin 1991). Presence of $\Psi$ in RNA helices has been shown to increase thermal stability without altering structure (Davis and Poulter 1991; Hall and McLaughlin 1991; Arnez and Steitz 1994; Kintanar et al. 1994; Durant and Davis 1999; Yarian et al. 1999), postulated to be the result of a water-mediated hydrogen bond involving the $\Psi \mathrm{N}^{1} \mathrm{H}$ (Arnez and Steitz 1994; Newby and Greenbaum 2002a) and/or improved base stacking (Yarian et al. 1999; Chui et al. 2002). In the case of the pre-mRNA branch site helix of the yeast spliceosome, the presence of a conserved $\Psi$ induces a strikingly different structure than that observed with uridine (Newby and Greenbaum 2001, 


\section{${ }_{2}^{5} \mathrm{GGUG} \Psi_{6} \mathrm{AGUA}_{10}^{33}$
${ }_{3}^{36} \mathrm{CCACA} \mathrm{A}_{23} \mathrm{UCAU}_{5}^{19}$,

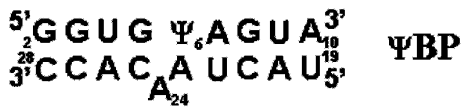

FIGURE 1. Sequences of the two RNA duplexes $\Psi_{\text {comp }}$ (top) and

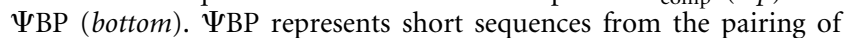
U2 snRNA (top strand) and the intron (bottom strand) from the yeast S. cerevisiae. The numbering scheme was that used in previous structure determination studies (Newby and Greenbaum, 2001, 2002a,b). The position of $\Psi$ ( $\Psi 6$ in this sequence) corresponds to a phylogenetically conserved $\Psi$ residue in U2 snRNA ( $\Psi 35$ in yeast). $\Psi_{\text {comp }}$ is a similar sequence without the bulged $\mathrm{A}$.

2002b). Structural models of the branch site duplex suggested that $\Psi$ did not appear to form a base pair with the opposing adenine (A23, adjacent to the bulged base, A24), and no resonance attributable to $\Psi \mathrm{N}^{3} \mathrm{H}$ was visible (Fig. 1). Identification of this resonance would contribute important information about the environment of this imino proton with respect to surrounding bases.

In order to slow the exchange of imino protons, we have acquired NMR spectra of two RNA duplexes containing $\Psi$ (Fig. 1) in aqueous solutions at supercooled temperatures by implementation of the capillary technique (Poppe and van Halbeek 1994). In addition to detecting imino protons corresponding to terminal base pairs of an RNA duplex, we observed the upfieldshifted $\mathrm{N}^{3} \mathrm{H}$ imino proton of a nonbase-paired $\Psi$ in the branch site duplex. Determining the role of $\Psi$ in stabilizing RNA structures may explain its phylogenetic conservation in the branch site helix and elsewhere in structural RNA molecules.

\section{RESULTS AND DISCUSSION}

We first acquired NMR spectra of pseudouridine monophosphate ( $\Psi M P)$ in order to characterize the resonances of its two imino protons, $\Psi \mathrm{N}^{1} \mathrm{H}$ and $\Psi$ $\mathrm{N}^{3} \mathrm{H}$, in a non-base-paired environment. Spectra of imino protons (including line widths) were identical for samples in capillaries and as a bulk sample at $0^{\circ} \mathrm{C}$ and $5^{\circ} \mathrm{C}$ (data not shown). The $\Psi \mathrm{N}^{1} \mathrm{H}$ and $\Psi \mathrm{N}^{3} \mathrm{H}$ proton chemical shifts were 10.6 and $10.8 \mathrm{ppm}$ and line-widths at half-height $\left(v_{1 / 2}\right)$ were $\sim 3.8$ and $\sim 5.1 \mathrm{~Hz}$ at $0^{\circ} \mathrm{C}$, respectively (Fig. $2 \mathrm{~A}$ ). Field Laboratory.
Upon cooling to $-15^{\circ} \mathrm{C}, \nu_{1 / 2}$ decreased monotonically ( $\sim 2.0$ and $\sim 2.7 \mathrm{~Hz}$ for $\mathrm{N}^{1} \mathrm{H}$ and $\mathrm{N}^{3} \mathrm{H}$, respectively), consistent with line narrowing associated with slower solvent exchange. $v_{1 / 2}$ of $\mathrm{N}^{1} \mathrm{H}$ was slightly larger than that of $\mathrm{N}^{3} \mathrm{H}$, presumably as a result of dipolar broadening from the proximal H6 proton of $\Psi\left(\sim 2.5\right.$ and $4.8 \AA$ between $\mathrm{H} 6$ and $\mathrm{N}^{1} \mathrm{H}$ and $\mathrm{N}^{3} \mathrm{H}$, respectively). We also observed a slight temperature dependence of chemical shift (thermal coefficient) for the imino protons. Positive thermal coefficients (i.e., more upfield chemical shift as a function of decreased temperature) correlate with rapid exchange, whereas negative thermal coefficients correlate with slower exchange, and are therefore consistent with hydrogen bonding (Nonin et al. 1995). We plotted the chemical shift with respect to temperature for each imino proton. The thermal coefficients for $\Psi \mathrm{N}^{1} \mathrm{H}$ and $\Psi \mathrm{N}^{3} \mathrm{H}$ were 6.1 and $5.3 \mathrm{ppb} /{ }^{\circ} \mathrm{C}$, respectively, consistent with a nonbase-paired environment for each proton (data not shown).

By comparison, NMR spectra of a complementary duplex ( $\left.\Psi_{\text {comp }}\right)$ (Fig. 1) indicate that all imino protons, including $\mathrm{N}^{3} \mathrm{H}$ of $\Psi$, participate in Watson-Crick base pairs (Fig. 2B). When $\Psi$ is in the anti-conformation, its $\mathrm{N}^{3} \mathrm{H}$
A

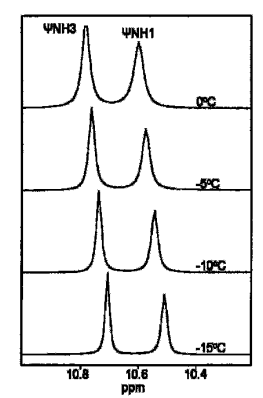

B

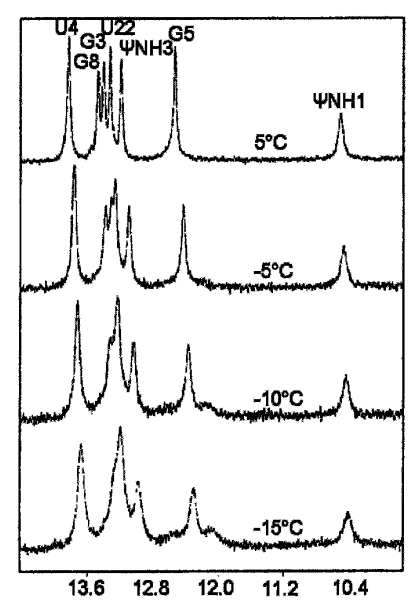

C

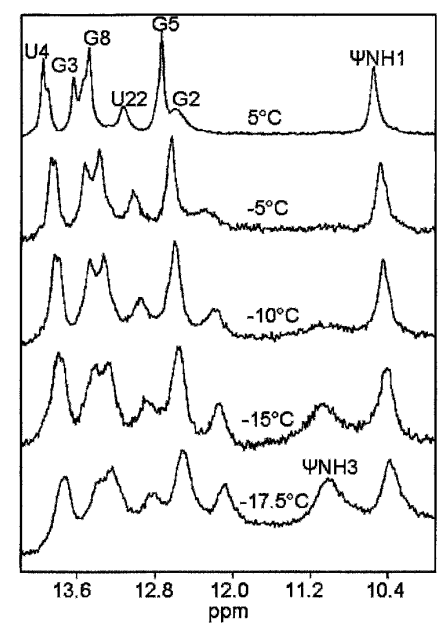

FIGURE 2. Imino proton spectra of $\Psi$-monophosphate ( $\Psi \mathrm{MP})(A), \Psi_{\text {comp }}(B)$, and $\Psi$ BP $(C)$ acquired at different temperatures between $5^{\circ} \mathrm{C}$ and $-17.5^{\circ} \mathrm{C}$. (A) $\Psi \mathrm{MP}(10 \mathrm{mM}$ in $10 \mathrm{mM} \mathrm{Na}$ phosphate at $\mathrm{pH} 6.4,50 \mathrm{mM} \mathrm{NaCl}, 0.1 \mathrm{mM}$ EDTA, in $90 \% \mathrm{H}_{2} \mathrm{O} / 10 \% \mathrm{D}_{2} \mathrm{O}$ ) was taken up into six capillary tubes, which were placed in a 5-mm NMR tube (fill factor of $\sim 0.25$ ). (B) $\Psi_{\text {comp }}$ (2.7-mM duplex) was prepared as in $A$ and was taken up into 10 capillary tubes, (fill factor of 0.4). (C) $\Psi \mathrm{BP}$ (2.5 mM duplex) was prepared as in $A$ and taken up into nine capillary tubes (fill factor of $\sim 0.3$ ). Data were collected using a jump-return-echo pulse sequence (Sklenár and Bax 1987) on a Varian $720-\mathrm{MHz}$ and $600-\mathrm{MHz}$ spectrometer at the National High Magnetic 
forms a hydrogen bond with the opposing adenine $\mathrm{N}^{1}$, reflected in the downfield shift of the imino proton resonance to 13.1 ppm (Fig. 2B; Hall and McLaughlin 1992; Durant and Davis 1999). Further confirmation of this assignment came from comparison of chemical shifts of a similar duplex in which $\Psi$ were replaced by uridine (U). We assigned the resonance at $10.6 \mathrm{ppm}$ to $\Psi \mathrm{N}^{1} \mathrm{H}$, which is on the major groove edge of the base when in an anti-conformation, based upon the chemical shift for this imino proton in $\Psi \mathrm{MP}$ and from observation of an NOE between it and the H6 proton ( $2.5 \AA$ away) (Hall and McLaughlin 1992; Newby and Greenbaum 2001). In order to determine how this proton is protected from rapid exchange with solvent, our previous studies made use of a CLEANEX-PM pulse sequence (Hwang et al. 1997) to characterize the interaction between $\Psi \mathrm{N}^{1} \mathrm{H}$ and water molecules (Newby and Greenbaum 2002a). For protons undergoing chemical exchange, this experiment determines whether there is a component of cross-relaxation. The spectrum acquired using a CLEANEXPM pulse sequence revealed a strong negative peak at the resonance location of $\Psi \mathrm{N}^{1} \mathrm{H}$ (but no other imino proton), indicating that the interaction with water is characterized by a significant component of cross-relaxation. This observation is consistent with participation of $\Psi \mathrm{N}^{1} \mathrm{H}$ in a water-mediated hydrogen bond with a phosphate oxygen atom of the same or a neighboring nucleotide. This hydrogen bonding status was predicted by Durant and Davis (1999), and visualized in a crystal structure of tRNA containing pseudouridine (Arnez and Steitz 1994).

At about $-10^{\circ} \mathrm{C}$, a broad peak appeared at $\sim 12.2 \mathrm{ppm}$ with a shoulder at $\sim 12.5 \mathrm{ppm}$. All imino protons of $\Psi_{\text {comp }}$ had previously been assigned except for those belonging to terminal base pairs (Fig. 2B); therefore, these new peaks were attributed to the imino protons of terminal residues. In contrast with the narrowing of peaks of the monophosphate at lower temperatures, broadening of peaks of the complementary duplex was observed below $0^{\circ} \mathrm{C}$ (line widths increased gradually from $\sim 50 \mathrm{~Hz}$ to $\sim 130 \mathrm{~Hz}$ ). The exact reasons for this behavior may be a complex combination of slower tumbling of the larger molecule as a result of increased solvent viscosity, salt and buffer effects, or may represent the beginning of cold denaturation.

We then performed similar experiments on a minimal premRNA branch site duplex of Saccharomyces cerevisiae ( $\Psi \mathrm{BP})$, which represents the pairing between a short consensus region of the U2 snRNA and the intron (Fig. 1). In contrast with the complementary duplex, presence of a $\Psi$ residue in the U2 snRNA strand of $\Psi B P$ (top strand in Fig. 1) in its conserved position (Yu et al. 1998; Ma et al. 2003) results in a very different conformation than in its unmodified counterpart (Newby and Greenbaum 2001, 2002b). In the novel $\Psi$ BP motif, the unpaired adenosine is extruded from the helix and forms a base triple with the minor groove edge of A7 in the A7-U22 base pair. The $2^{\prime} \mathrm{OH}$ of this extrahelical adenosine is the nucleophile in the first cleavage step of splicing. The structural motif preferred in the presence of this $\Psi$ ( $\Psi 35$ in the native yeast sequence) may explain the strong phylogenetic preservation of this modified base in this location. In $\Psi \mathrm{BP}$, the chemical shift of $\Psi \mathrm{N}^{1} \mathrm{H}$ is $\sim 10.5$ ppm (vs. $\sim 10.6 \mathrm{ppm}$ in $\Psi \mathrm{MP}$ and $\Psi_{\text {comp }}$ ). As was observed in $\Psi_{\text {comp }}$, previous NMR investigation of the interaction of $\Psi \mathrm{N}^{1} \mathrm{H}$ of $\Psi \mathrm{BP}$ indicated that this proton undergoes crossrelaxation with water molecule(s) in the major groove of the duplex (Newby and Greenbaum 2002a). Unlike the case with $\Psi_{\text {comp }}$, proton spectra of $\Psi$ BP revealed no resonance attributable to $\Psi \mathrm{N}^{3} \mathrm{H}$, and structural models did not indicate formation of a base pair between $\Psi$ and the opposing adenine (A23, adjacent to the branch site base A24).

In order to identify the resonance location of the absent (and presumably exchange broadened) $\Psi \mathrm{N}^{3} \mathrm{H}$ in the branch site duplex at $0^{\circ} \mathrm{C}-5^{\circ} \mathrm{C}$, we acquired spectra of $\Psi B P$ in supercooled water (Fig. 2C). As in spectra of the complementary duplex, a broad new peak emerged at $\sim 12.2$ ppm below $-5^{\circ} \mathrm{C}$, corresponding to the $\mathrm{G} 2$ terminal base pair. The imino proton of the other terminal base pair may be degenerate with a resonance at $\sim 13.3 \mathrm{ppm}$. Unique to the branch site duplex, a broad peak emerged at $\sim 11.2 \mathrm{ppm}$ at $-15^{\circ} \mathrm{C}$. Because assignments of all other imino protons of the branch site helix were made by systematic comparison with other duplexes (Newby and Greenbaum 2002b), we identified this upfield-shifted resonance as that of $\Psi \mathrm{N}^{3} \mathrm{H}$. No NOEs were observed from this broad peak. The $\Psi \mathrm{N}^{3} \mathrm{H}$ chemical shift was close to that of the unpaired $\mathrm{N}^{3} \mathrm{H}$ of $\Psi \mathrm{MP}$, which is not base paired (Fig. 2A) and very different from that of the Watson-Crick paired $\Psi$ of $\Psi_{\text {comp }}$ (Fig. 2B). The upfield location of $\Psi \mathrm{N}^{3} \mathrm{H}$ of $\Psi \mathrm{BP}$ (Fig. 2C) further supports our original finding that $\Psi 6$ does not form a canonical base pair with A23 (Newby and Greenbaum 2002b). As with $\Psi_{\text {comp }}$, line widths began to broaden below $0^{\circ} \mathrm{C}$, increasing from $\sim 50 \mathrm{~Hz}$ to $\sim 200 \mathrm{~Hz}$.

We noted that chemical shifts of each imino proton varied slightly with a decrease in temperature. We therefore generated a thermal coefficient for each imino proton resonance by plotting the chemical shifts as a function of temperature (Fig. 3). For $\Psi_{\text {comp }}$, negative thermal coefficients (more downfield shifts with respect to decreased temperature) were observed for all protons except the terminal imino proton (Fig. 3, top). The thermal coefficient for $\Psi \mathrm{N}^{1} \mathrm{H}$ and $\Psi \mathrm{N}^{3} \mathrm{H}$ was $-6.2 \mathrm{ppb} /{ }^{\circ} \mathrm{C}$ and $-0.7 \mathrm{ppb} /{ }^{\circ} \mathrm{C}$, respectively, suggesting that both form hydrogen bonds (Newby and Greenbaum 2001, 2002a,b). The thermal coefficient for G2 was positive, consistent with rapid exchange expected for a solvent-exposed terminal base pair.

In $\Psi B P$, protons with negative thermal coefficients belonged to G8, G5, G3, U4, and $\Psi \mathrm{N}^{1} \mathrm{H}$, and those with positive thermal coefficients were G2, U22, and $\Psi \mathrm{N}^{3} \mathrm{H}$ (Fig. 3, bottom). The negative thermal coefficient for $\Psi$ 

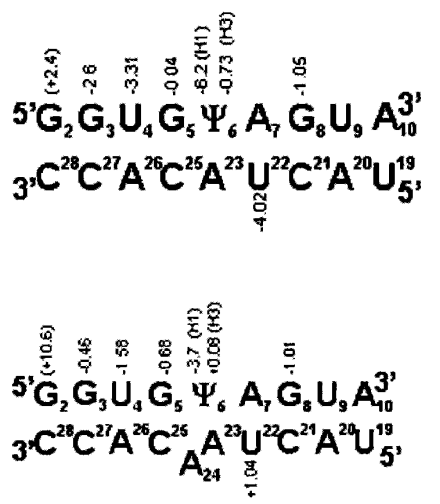

FIGURE 3. Thermal coefficients for $\Psi_{\text {comp }}$ (top) and $\Psi$ BP (bottom). The chemical shift for each proton was plotted as a function of temperature at which the spectrum was acquired. The value (in $\mathrm{ppb} /{ }^{\circ} \mathrm{C}$ ) for each imino proton is shown next to its position in the sequence. Positive thermal coefficients correlate with rapid exchange and negative thermal coefficients correlate with hydrogen bonding (Nonin et al. 1995). See text for further details.

$\mathrm{N}^{1} \mathrm{H}\left(-3.7 \mathrm{ppb} /{ }^{\circ} \mathrm{C}\right)$ reinforced the conclusion that this imino proton is involved in a hydrogen bond, as suggested by the results of earlier NMR studies (Newby and Greenbaum 2002a). The thermal coefficient of U22 was $1.03 \mathrm{ppb} /{ }^{\circ} \mathrm{C}$ and that of $\Psi \mathrm{N}^{3} \mathrm{H}$ was $0.08 \mathrm{ppb} /{ }^{\circ} \mathrm{C}$. Although $\mathrm{U} 22$ forms a Watson-Crick base pair with A7, its involvement in the base triple with the branch site $\mathrm{A}$ and its position adjacent to the unpaired $\Psi$ exposes $\mathrm{U} 22 \mathrm{~N}^{3} \mathrm{H}$ to solvent, which apparently increases its exchange rate. For $\Psi \mathrm{N}^{3} \mathrm{H}$, this positive value is in accord with rapid exchange, suggesting the proton is not involved in a hydrogen bond. This observation, combined with its upfield-shifted position and lack of NOEs to surrounding residues, especially the adjacent $\mathrm{A}^{2} \mathrm{H}$, is entirely consistent with our original conclusion about this $\Psi$ 's non-base-paired status (Newby and Greenbaum 2002b) and assists in further refinement of the $\Psi B P$ structure.

In conclusion, NMR data at low temperatures allow us to identify imino protons that are undetected at higher temperatures due to rapid exchange. This technique may be helpful in structure determination of non-base-paired regions of novel RNA motifs and for extending the temperature range over which chemical shift data can be acquired. Applying the capillary technique appears to be promising for NMR in supercooled water using other interesting biomolecules.

\section{MATERIALS AND METHODS}

\section{Design and synthesis of samples}

The solutions of RNA we used were the pseudouridine monophosphate ( $\Psi \mathrm{MP})$, a complementary RNA duplex ( $\Psi_{\text {comp}}$, $5^{\prime}$-GGUG $\Psi$ AGUA-3' vs. 5'-UACUACACC-3') (shown in Fig. 1, top), and an RNA duplex with a bulged adenosine, representing a minimal form of the pre-mRNA branch site from $S$. cerevisiae ( $\Psi \mathrm{BP}, 5^{\prime}$-GGUG $\Psi$ AGUA- $3^{\prime}$ vs. $5^{\prime}$-UACUAACACC- $3^{\prime}$; bulged A is underlined) (Fig. 1, bottom). Pseudouridine monophosphate was purchased from Berry and Associates (no. PYA11080). RNA oligomers were purchased from Dharmacon Research and deprotected according to company protocol (Wincott et al. 1995). Samples were precipitated with ethanol, partially desalted by three washes of the pelleted RNA with $80 \%$ ethanol, and lyophilized to dryness. The RNA pellets were then resuspended in diethyl pyrocarbonate-treated (DEPC) water, and strand concentrations were calculated from the absorbance at $260 \mathrm{~nm}$. Equimolar amounts of the strands were combined to obtain duplexes of the $\Psi_{\text {comp }}$ and $\Psi$ BP and verified by mobility on a nondenaturing gel. The duplexes were lyophilized to dryness and resuspended in $250 \mu \mathrm{L}$ of NMR buffer consisting of $10 \mathrm{mM}$ sodium phosphate ( $\mathrm{pH}$ 6.4), $50 \mathrm{mM}$ sodium chloride, and $0.1 \mathrm{mM}$ EDTA in $90 \%$ $\mathrm{H}_{2} \mathrm{O} / 10 \% \mathrm{D}_{2} \mathrm{O}$ (99.96\%; Cambridge Isotope Laboratories). Final concentration of RNA strands in NMR samples was $\sim 2.7 \mathrm{mM}$ for $\Psi_{\text {comp }}$ and $\sim 2.5 \mathrm{mM}$ for $\Psi$ BP. NMR assignments of imino protons of $\Psi B P$ were reported previously (Newby and Greenbaum 2001, 2002b).

\section{Sample preparation}

Open-ended glass capillaries of $1.0 \mathrm{~mm}$ OD were purchased from Fisher (no. 34500-99). The capillaries were prepared by soaking in $100 \%$ methanol overnight and then dried at $170^{\circ} \mathrm{C}$. Solutions of RNA were centrifuged at $14,000 \mathrm{rpm}$ for $30 \mathrm{~min}$ in order to remove particles that could nucleate ice crystals. The samples were then taken up by capillary action with $\sim 27 \mu \mathrm{L}$ in each capillary. The ends of the open capillaries were flamed sealed, and the capillaries were placed in a $5-\mathrm{mm}$ NMR tube (Poppe and van Halbeek 1994; Skalicky et al. 2000, 2001). Bundles of 9-10 capillaries have a filling factor of $30 \%-40 \%$ to yield an effective concentration of $\sim 1 \mathrm{mM}$ for the two RNA duplexes; $\Psi \mathrm{MP}$, with a starting concentration of $10 \mathrm{mM}$ in six capillaries, had an effective concentration of $\sim 2.5 \mathrm{mM}$.

\section{NMR spectroscopy}

NMR spectra were acquired on a $720-\mathrm{MHz}$ and $600-\mathrm{MHz}$ Varian Unity Plus spectrometers (National High Magnetic Field Laboratory). Samples were cooled at a rate of $-1.5^{\circ} \mathrm{C} / \mathrm{h}$ to $-2.5^{\circ} \mathrm{C} / \mathrm{h}$ with an increase in rate as the temperature decreased. The jump-return echo pulse sequence (Sklenár and Bax 1987) was used to array the temperature decrease in order to observe the imino protons at different temperatures, and freezing of one or more capillaries was monitored by a proportional decrease in signal intensity, but no capillary tubes broke. We used 64 steady-state scans prior to each acquisition. In order to improve signal quality at lower temperatures, we doubled the number of acquisitions for each incremental temperature decrease of $2.5^{\circ} \mathrm{C}: 128$ at $-5^{\circ} \mathrm{C}, 512$ scans for $-10^{\circ} \mathrm{C}$, and up to 4096 scans at $-17.5^{\circ} \mathrm{C}$. Processing of NMR data and simulation line-width at half height were accomplished using Felix 2.3 (Biosyn). 


\section{ACKNOWLEDGMENTS}

We thank the National High Magnetic Laboratory and the Nuclear Magnetic Resonance Laboratory in the Department of Chemistry and Biochemistry at FSU for the use of their NMR facilities. This material is based upon work supported by the National Science Foundation under Grant No. 0316494 and by the National Institutes of Health Grant GM54008.

Received February 7, 2005; accepted April 20, 2005.

\section{REFERENCES}

Angell, C.A. 1982. In water: A comprehensive treatise. Plenum Press, New York.

Arnez, J.G. and Steitz, T.A. 1994. Crystal structure of unmodified tRNA(Gln) complexed with glutaminyl-tRNA synthetase and ATP suggests a possible role for pseudo-uridines in stabilization of RNA structure. Biochemistry 33: 7560-7567.

Chui, H.M., Desaulniers, J.P., Scaringe, S.A., and Chow, C.S. 2002. Synthesis of helix 69 of Escherichia coli 23S rRNA containing its natural modified nucleosides, $\mathrm{m}(3) \Psi$ and $\Psi$. J. Org. Chem. 67: 8847-8854.

Davis, D.R. and Poulter, C.D. 1991. ${ }^{1} \mathrm{H}^{15} \mathrm{~N}$ NMR studies of Escherichia coli tRNA(Phe) from hisT mutants: A structural role for pseudouridine. Biochemistry 30: 4223-4231.

Durant, P.C. and Davis, D.R. 1999. Stabilization of the anticodon stem-loop of tRNA ${ }^{\text {Lys,3 }}$ by an A+-C base-pair and by pseudouridine. J. Mol. Biol. 285: 115-131.

Hall, K.B. and McLaughlin, L.W. 1991. Properties of a U1/mRNA 5' splice site duplex containing pseudouridine as measured by thermodynamic and NMR methods. Biochemistry 30: 1795-1801.

- 1992. Properties of pseudouridine $\mathrm{N}^{1}$ imino protons located in the major groove of an A-form RNA duplex. Nucleic Acids Res. 20: $1883-1889$.

Hwang, T.L., Mori, S., Shaka, A.J., and vanZijl, P.C.M. 1997. Application of phase-modulated CLEAN chemical EXchange spectroscopy (CLEANEX-PM) to detect water-protein proton exchange and intermolecular NOEs. J. Am. Chem. Soc. 119: 6203-6204.

Kerwood, D.J., Cavaluzzi, M.J., and Borer, P.N. 2001. Structure of SL4 RNA from the HIV-1 packaging signal. Biochemistry 40: 14518-14529.
Kintanar, A., Yue, D., and Horowitz, J. 1994. Effect of nucleoside modifications on the structure and thermal stability of Escherichia coli valine tRNA. Biochimie 76: 1192-1204.

Ma, X., Zhao, X., and Yu, Y.T. 2003. Pseudouridylation ( $\Psi)$ of U2 snRNA in $S$. cerevisiae is catalyzed by an RNA-independent mechanism. EMBO J. 22: 1889-1897.

Newby, M.I. and Greenbaum, N.L. 2001. A conserved pseudouridine modification in eukaryotic U2 snRNA induces a change in branchsite architecture. RNA 7: 833-845.

- 2002a. Investigation of Overhauser effects between pseudouridine and water protons in RNA helices. Proc. Natl. Acad. Sci. 99: 12697-12702.

- 2002b. Sculpting of the spliceosomal branch site recognition motif by a conserved pseudouridine. Nat. Struct. Biol. 9: 958-965.

Nonin, S., Leroy, J.L., and Gueron, M. 1995. Terminal base pairs of oligodeoxynucleotides: Imino proton exchange and fraying. Biochemistry 34: 10652-10659.

Poppe, L. and van Halbeek, H. 1994. NMR spectroscopy of hydroxyl protons in supercooled carbohydrates. Nat. Struct. Biol. 1: 215-216.

Skalicky, J.J., Sukumaran, D.K., Mills, J.L., and Szyperski, T. 2000. Toward structural biology in supercooled water. J. Am. Chem. Soc. 122: $3230-3231$.

Skalicky, J.J., Mills, J.L., Sharma, S., and Szyperski, T. 2001. Aromatic ring-flipping in supercooled water: Implications for NMR-based structural biology of proteins. J. Am. Chem. Soc. 123: 388-397.

Sklenár, V. and Bax, A. 1987. Spin-echo water suppression for the generation of pure-phase two-dimensional NMR-spectra. J. Magn. Reson. 74: 469-479.

Wincott, F., DiRenzo, A., Shaffer, C., Grimm, S., Tracz, D., Workman, C., Sweedler, D., Gonzalez, C., Scaringe, S., and Usman, N. 1995. Synthesis, deprotection, analysis and purification of RNA and ribozymes. Nucleic Acids Res. 23: 2677-2684.

Yarian, C.S., Basti, M.M., Cain, R.J., Ansari, G., Guenther, R.H., Sochacka, E., Czerwinska, G., Malkiewicz, A., and Agris, P.F. 1999. Structural and functional roles of the $\mathrm{N}^{1}$ - and $\mathrm{N}^{3}$-protons of $\Psi$ at tRNA's position 39. Nucleic Acids Res. 27: 3543-3549.

Yu, Y.T., Shu, M.D., and Steitz, J.A. 1998. Modifications of U2 snRNA are required for snRNP assembly and pre-mRNA splicing. EMBO J. 17: $5783-5795$. 

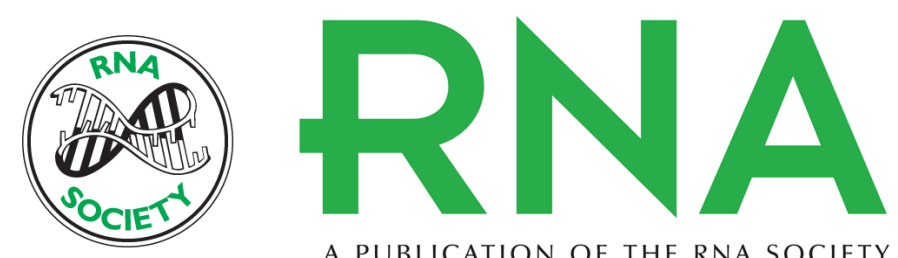

A PUBLICATION OF THE RNA SOCIETY

\section{NMR spectroscopy of RNA duplexes containing pseudouridine in supercooled water}

KERSTEN T. SCHROEDER, JACK J. SKALICKY and NANCY L. GREENBAUM

RNA 2005 11: 1012-1016

References This article cites 21 articles, 4 of which can be accessed free at:

http://rnajournal.cshlp.org/content/11/7/1012.full.html\#ref-list-1

\section{License}

Email Alerting Receive free email alerts when new articles cite this article - sign up in the box at the Service top right corner of the article or click here. 